SISTEMA
ELETRONNICO
DE REVISTAS
SER I UFPR

\title{
A pesca artesanal no município de Penha (SC): uma releitura do contexto socioeconômico da atividade e da capacidade adaptativa do setor
}

\section{Artisanal fisheries in the city of Penha (SC): a rereading of socioeconomic context of the activity and the sector adaptive capacity}

\author{
Renata Costella ACAUAN ${ }^{1 *}$, Joaquim Olinto BRANCO ${ }^{2}$, Benjamim TEIXEIRA ${ }^{1}$, Jorge Luiz RODRIGUES \\ FILHO $^{3,4}$, Marcus POLETTE ${ }^{2}$ \\ ${ }^{1}$ Instituto Federal de Educação Ciência e Tecnologia de Santa Catarina (IFSC), Itajaí, SC, Brasil. \\ ${ }^{2}$ Universidade do Vale do Itajaí (UNIVALI), Itajaí, SC, Brasil. \\ ${ }^{3}$ Programa de Pós-Graduação em Planejamento Territorial e Desenvolvimento Socioambiental (PPGPLAN), Universidade do Estado de Santa \\ Catarina (UDESC), Florianópolis, SC, Brasil. \\ ${ }^{4}$ Laboratório de Ecologia, Departamento de Engenharia de Pesca e Ciências Biológicas, Universidade do Estado de Santa Catarina (UDESC), \\ Laguna, SC, Brasil. \\ *E-mail de contato: renataacauan@gmail.com
}

Artigo recebido em 22 de fevereiro de 2018, versão final aceita em 23 de agosto de 2018.

RESUMO: A pesca artesanal está inserida no contexto de milhares de comunidades ao redor do mundo, contribuindo para a erradicação da pobreza, no desenvolvimento das comunidades e na utilização sustentável dos recursos naturais. No Brasil, estima-se que mais de um milhão de pessoas estejam diretamente envolvidas com a atividade pesqueira, a maioria na pesca artesanal. Muitos são, no entanto, os desafios do setor, incluindo a eficiência das políticas públicas e o amplo conhecimento das realidades locais. Sendo assim, buscou-se identificar o contexto socioeconômico dos pescadores artesanais no município de Penha (SC), de forma a compreender as mudanças ocorridas nos últimos anos, e as estratégias da comunidade quanto à atividade. Para isso, foi caracterizada a principal modalidade de pesca no município, seus atores, suas relações, limitações e conflitos. Os dados foram obtidos por meio de entrevistas semiestruturadas, conversas informais e observações, utilizando-se princípios de pesquisa participativa e pesquisa-ação, além de dados secundários e pesquisa bibliográfica. Os resultados mostram que a pesca artesanal está inserida no cotidiano do município, embora mudanças significativas venham ocorrendo nos processos produtivos ao longo dos anos. Foram observados indícios de que os pescadores se adaptam às mudanças, e têm mantido a pesca como uma importante fonte de renda no município, inclusive com incremento de seus rendimentos. Algumas mudanças no perfil do pescador 
nos últimos anos foram constatadas, assim como uma renovação, por meio de trabalhadores que migraram da pesca industrial. Indo de encontro a diversos estudos sobre a pesca artesanal no Brasil, a atividade vem se mantendo no município, apresentando indicativos de crescimento tanto em número de embarcações e pescadores, quanto em produção e renda. É necessário, porém, que se estabeleça um monitoramento da pesca artesanal, permitindo uma análise mais ampla do contexto socioeconômico e ambiental, pois a escassez de alguns dados prejudica a formulação de políticas públicas e consequentemente o desenvolvimento do setor.

Palavras-chave: aspectos socioeconômicos; Xiphopenaeus kroyeri; pescado.

ABSTRACT: Artisanal fisheries are insert in the context of thousands of communities around the world, contributing to the eradication of poverty, community development and the sustainable use of natural resources. In Brazil, it is estimated that more than one million people are directly involved in fishing activity, mostly in artisanal fisheries. There are, however, many challenges to the industry, including the efficiency of public policies and a broad understanding of local realities. Therefore, socioeconomic aspects of the artisanal fisheries was evaluated in Penha, Santa Catarina state, to understand how fishermen responded to changes in activity in recent years and which were the strategies adopted to them in mentioned situation. For this, the main modality of fishing in the municipality, its actors, their relations, limitations and conflicts were characterized. Data were obtained through semi-structured interviews, informal conversations and observations, using principles of participatory research and action research, as well as secondary data and bibliographic research. The results show that artisanal fishing is part of the city daily life, although significant changes have been occurring in the productive processes over the years. There have been indications that fishermen adapt to changes and have maintained fishing as an important source of income in the city, including an increase in their own earnings. Some changes in the profile of the fisherman in recent years have been noted, as well as a renewal, by workers who have migrated from industrial fishing. Going against several studies on artisanal fishing in Brazil, the activity has been maintained in the city, presenting indicators of growth both in number of vessels and fishermen, as well as in production and income. It is necessary, however, to establish a monitoring of artisanal fishing, allowing a broader analysis of the socioeconomic and environmental context, because the scarcity of some data harms the formulation of public policies and consequently the development of the sector.

Keywords: socioeconomic aspects; Xiphopenaeus kroyeri; fish.

\section{Introdução}

A pesca artesanal e de pequena escala desempenha um papel importante na erradicação da pobreza, no desenvolvimento das comunidades e na utilização sustentável dos recursos naturais, contribuindo com cerca de dois terços das capturas de pescado destinado ao consumo humano no mundo (Kurien, 2015). O setor emprega mais de $90 \%$ dos pescadores, cerca de metade dos quais são mulheres; estes trabalhadores, no entanto, nem sempre estão visíveis aos olhos das políticas públicas (Eler \& Millani, 2007; Gillett, 2010), comprometendo as estratégias de gestão e sua sustentabilidade (Iles, 2007).

A pesca artesanal, ao redor do mundo, está inserida em redes complexas, dinâmicas e múltiplas, de fornecimento e comércio que ligam a produção ao consumo, envolvendo processos de agregação de valor e criação de emprego ao longo do caminho, envolvendo mais de 80 milhões de pessoas (Jacinto \& Pomeroy, 2011). O maior fator 
limitante nos países em desenvolvimento é uma grave falta de dados que impede os pesquisadores de demonstrar de maneira mais rigorosa e confiável a verdadeira importância das pescarias em pequena escala (Béné, 2006).

Ao que tudo indica, os atuais modelos de gestão aplicados para a pesca artesanal não têm sido eficientes, pois a maioria está baseada num objetivo único de manter os estoques em níveis sustentáveis. É preciso que os objetivos tenham caráter múltiplo, incluindo fatores biológicos, econômicos, sociais e culturais (Berkes, 2001; Castello, 2008; Viegas, 2012), considerando a dimensão humana na pesca (Bené, 2006; Allison et al., 2012). Para isso, é imperativo que se conheça a realidade socioambiental das comunidades, pois as políticas e estratégias de gestão dependem também do acesso a informações amplas e contínuas (Rosales et al., 2017).

No Brasil, a pesca marinha e costeira representa uma produção aproximada de $760 \mathrm{mil}$ toneladas onde a pesca artesanal representa $30 \%$ da produção nacional. (MPA, 2015; FAO, 2016). Estão cadastrados mais de um milhão de pescadores no país (Dias Neto, 2017), a maioria atuando na pesca artesanal; no entanto estes dados podem estar contabilizando também os trabalhadores do apoio a pesca, frequentemente cadastrados como pescadores artesanais. A falta de informações oficiais e estudos mais abrangentes sobre a produção pesqueira artesanal no Brasil reflete em políticas públicas inadequadas ou ausentes, assim como acontece em muitos países em desenvolvimento (Eler \& Millani, 2007).

Principal produtor nacional de pescados, o estado de Santa Catarina concentra mais de $34 \mathrm{mil}$ pescadores, a maioria artesanais, atividade que representa $30 \%$ da produção de pescados no Estado
(MPA, 2011; UNIVALI, 2015; Dias Neto, 2017). No município de Penha, litoral norte de Santa Catarina, a pesca artesanal é uma das principais atividades econômicas, sendo a pesca de arrasto a mais praticada para a captura do camarão (principalmente da espécie sete-barbas, Xiphopenaeuskroyeri). Há também uma série de outras atividades econômicas que constituem a cadeia produtiva do pescado no município, incluindo o comércio local de pescados (in natura, beneficiados e processados), o beneficiamento, os serviços e o turismo.

Apesar de muitas pesquisas abordarem a pesca artesanal no município de Penha (Almeida \& Branco, 2002; Bail \& Branco, 2003; Branco \& Fracasso, 2004; Branco, 2005; Branco \& Verani, 2006; Bail \& Branco, 2007; Branco et al., 2013; Coelho et al., 2016), apontando diversos problemas relacionados à atividade, poucas mudanças são observadas neste cenário. Certamente porque o contexto da pesca vai muito além dos dados de produção pesqueira, ou mesmo de uma descrição socioeconômica. Há um emaranhado de atores envolvidos direta ou indiretamente com a atividade, há um contexto político, legal e institucional, um contexto ecológico, e ainda os aspectos econômicos. No entanto, muito pouco se conhece sobre todas estas relações e, para que se possa supor sobre o futuro da atividade, é preciso primeiro identificar e compreender o cenário existente, numa abordagem integrada.

Observa-se que muitos estudos sobre a pesca artesanal no Brasil sugerem um possível declínio desta atividade, pela ausência de renovação do público, interpretada pela idade dos pescadores, e a consequente futura estagnação desta atividade (Santos et al., 1995; Medeiros, 2002; Garcez \& Botero, 2005; Souza et al., 2009; Sedrez et al., 2013; Silva-Gonçalves \& D'Incao, 2016; Mendonça et 
al., 2017). Neste sentido, infere-se uma hipótese de releitura do cenário da pesca artesanal no município de Penha, por meio do atual contexto socioeconômico, visto que a atividade continua sendo desenvolvida ao longo dos anos, mesmo diante do atual cenário da gestão pesqueira.

Analisar os aspectos socioeconômicos da pesca e as estratégias da comunidade torna-se fundamental para uma melhor gestão da atividade e dos recursos naturais. Sendo assim, buscou-se constituir uma releitura do contexto socioeconômico da pesca artesanal no município de Penha (SC), com destaque para a pesca de arrasto do camarão sete-barbas, identificando os principais atores, suas relações, limitações e conflitos.

\section{Materiais e métodos}

A área de estudo contempla o município de Penha, localizado no litoral centro-norte de Santa Catarina ( $26^{\circ} 46^{\prime} \mathrm{S}$ e $48^{\circ} 38^{\prime} \mathrm{W}$, Fig. 1), com área de $58.748 \mathrm{~km}^{2}$, e população estimada de 30.262 habitantes (IBGE, 2017), limitando-se ao Sul com Navegantes, ao Oeste e Norte com Piçarras e a Leste com o oceano Atlântico. A economia do município está impulsionada pelo turismo, enquanto cresce a atividade de maricultura, mas a pesca artesanal nas três comunidades indicadas na Figura 1 é uma das principais atividades, tradicionalmente realizada no município, envolvendo um grande número de famílias, (Branco, 2005).

Os dados utilizados na pesquisa foram obtidos utilizando-se princípios de pesquisa participativa e pesquisa-ação, considerando a práxis social como ponto de partida e de chegada e realizada no ambiente natural da realidade a ser pesquisada
(Thiollent, 2002; Koerichet al., 2009). A coleta de dados foi baseada em entrevistas semiestruturadas, observações e dados secundários, realizadas entre março de 2016 e agosto de 2017. O público envolvido foram pescadores, familiares, representantes de instituições e demais atores identificados no decorrer da pesquisa, totalizando 54 intervenções, considerando um universo de 159 pescadores no município (Acauan et al., 2018).

$O$ roteiro das entrevistas constava de questões divididas em três aspectos: caracterização do pesca-
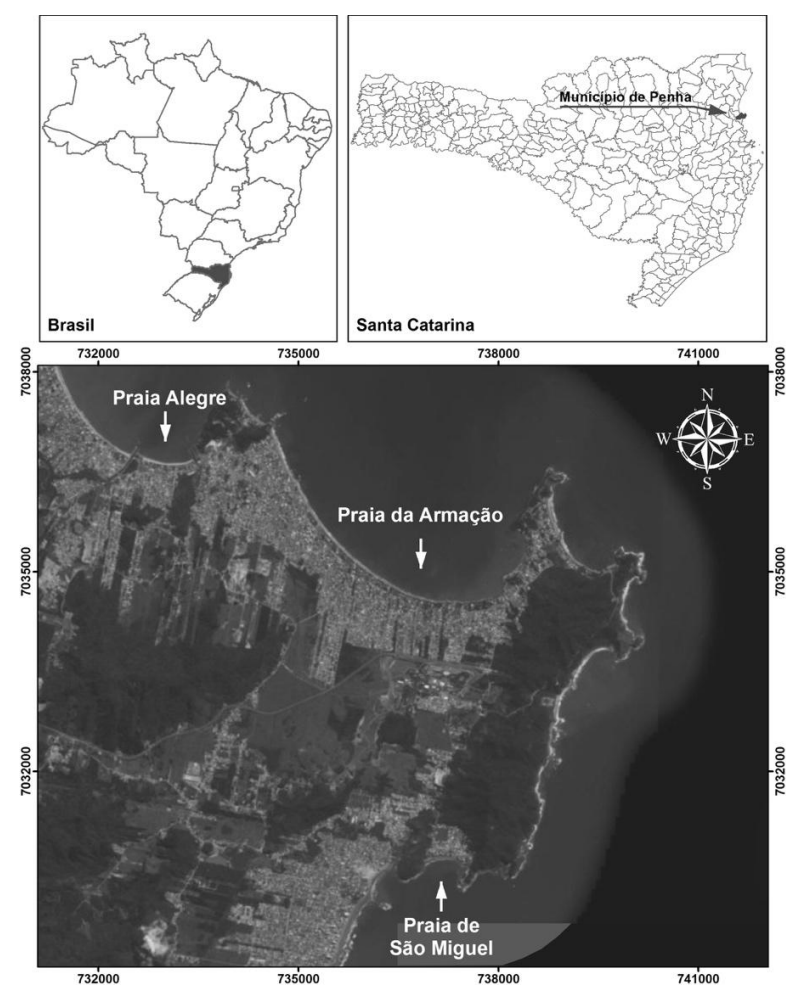

FIGURA 1 - Localização da área de estudo, indicando as principais comunidades pesqueiras artesanais do município de Penha, SC.

FONTE: Elaborado pelo autor. 
dor, caracterização da atividade de pesca e aspectos da comunidade, todos com perguntas relacionadas à pesca artesanal do camarão sete-barbas. Algumas perguntas tinham o objetivo de confirmar ou negar as respostas de perguntas anteriores, sendo que os questionamentos foram realizados por meio de diálogo entre o pesquisador e o entrevistado. Os dados foram posteriormente tabulados em planilha eletrônica, elaboradas tabelas, gráficos, médias calculadas e erro padrão, em alguns casos.

Antes da realização de cada entrevista, o entrevistado assinou um termo de consentimento livre esclarecido, no qual concordou em conceder uma entrevista com finalidade de pesquisa acadêmica, estando preservado o anonimato dos participantes.

As observações foram realizadas mediante um contato direto com o ambiente de estudo, para o acompanhamento de diferentes aspectos da atividade pesqueira (chegada das embarcações, comercialização, tarefas diárias). Foram realizadas mediante planejamento e registro, com posterior verificação por meio de outros dados (Marconi \& Lakatos, 2002).

Pesquisa de campo preliminar foi realizada para identificar o quantitativo de embarcações, por meio de contagem visual nos principais locais de atracação e fundeio do município (Aramação do Itapocoroy, Praia de São Miguel e Praia Alegre) em três momentos diferentes, sempre ao final da tarde. Também foram realizadas intervenções para obtenção de informações em entidades e estabelecimentos locais, além da pesquisa bibliográfica, buscando caracterizar as relações existentes entre os diferentes atores que compõem as atividades no município. Foram ainda utilizados dados secundários, provenientes de órgãos oficiais, publicações e instituições locais.

\section{Resultados e discussão}

\subsection{Aspectos socioeconômicos da atividade pesqueira: uma releitura}

O perfil socioeconômico do pescador artesanal do município de Penha foi identificado, permitindo a proposição de algumas comparações com dados obtidos por Branco et al. (2006) e por meio do Projeto Caracterização socioeconômica das atividades de pesca e aquicultura em Santa Catarina (UNIVALI, 2015), para o mesmo município (Tabela 1), bem como com trabalhos para outras comunidades pesqueiras. A partir dos dados foi possível discutir alguns aspectos socioeconômicos, no intuito de compreender os fatores de adaptabilidade da comunidade pesqueira ao longo dos anos, bem como as possíveis mudanças no seu perfil.

A idade dos pescadores entrevistados variou entre 23 e 72 anos, sendo a faixa etária predominante entre 41 e 50 anos. Os dados assemelham-se aos obtidos por Branco et al. (2006) em estudo sobre a caracterização dos pescadores no mesmo local de estudo (faixa etária predominante entre 40 e 50 anos), e aos dados de UNIVALI (2015), demostrando que estes trabalhadores tem um perfil de idade semelhante a outras comunidades pesqueiras, mantendo-se ao longo dos últimos 10 anos. Partindo-se da hipótese de que não há uma considerável renovação na comunidade pesqueira artesanal (entrada de novos pescadores), esperava-se que a faixa etária média fosse mais elevada, já que quase a metade dos pescadores em 2006 tinha entre 40 e 50 anos, o que não foi observado.

Esse perfil de faixa etária mais elevada dos pescadores vem sendo interpretado em diversos 
TABELA 1 - Dados socioeconômicos dos pescadores artesanais de Penha (SC) identificados na pesquisa (2017), comparados aos dados de Branco et al. (2006) e UNIVALI (2015).

\begin{tabular}{|c|c|c|c|}
\hline & $\begin{array}{c}2006 \\
\text { (Branco } \text { et al., 2006) }\end{array}$ & $\begin{array}{c}2015 \\
\text { (UNIVALI, 2015) }\end{array}$ & $\begin{array}{c}2017 \\
\text { (Pesquisa de campo) }\end{array}$ \\
\hline Faixa etária predominante & $40-50$ anos & 45,21 anos (média) & $41-50$ anos \\
\hline Escolaridade & $\begin{array}{l}\text { Fundamental incompleto }(65,5 \%) \\
\text { Médio completo }(1,8 \%)\end{array}$ & - & $\begin{array}{l}\text { Fundamental incompleto }(45,2 \%) \\
\text { Médio completo }(22,6 \%)\end{array}$ \\
\hline $\begin{array}{l}\text { Renda mensal predomi- } \\
\text { nante }\end{array}$ & Até 2 salários mínimos $(76,3 \%)$ & $\begin{array}{l}\text { 2,29 salários mínimos } \\
\text { (média) }\end{array}$ & $\begin{array}{l}\text { Acima de } 2 \text { salários mínimos } \\
(72,2 \%)\end{array}$ \\
\hline Colônia de pesca & Filiados $97,7 \%$ & Filiados a entidades $76 \%$ & Filiados $61,1 \%$ \\
\hline Pesca industrial & Atuou outra comunidade $78,0 \%$ & - & Atuou pesca industrial $63,9 \%$ \\
\hline Continuidade na profissão & Pretendem continuar $76,4 \%$ & - & Pretendem continuar $95,0 \%$ \\
\hline
\end{tabular}

FONTE: Elaborado pelo autor, com base nos dados de Branco et al. (2006), UNIVALI (2015) e na pesquisa de campo.

estudos sobre comunidades pesqueiras como uma tendência de envelhecimento ou senilização da pesca (Santos et al., 1995; Medeiros, 2002; Garcez \& Botero, 2005; Souza et al., 2009; Sedrez et al., 2013; Silva-Gonçalves \& D'Incao, 2016; Mendonça et al., 2017). O que se observa no município em estudo, no entanto, é que $63,9 \%$ dos pescadores entrevistados afirmam estar atuando na pesca artesanal após terem trabalhado na pesca industrial; pode-se observar que há uma renovação do público da pesca nesta comunidade, por meio destes trabalhadores, porém não há entrada significativa de público mais jovem, mas sim dos trabalhadores que migraram da pesca industrial. Pesquisa de Sedrez et al. (2013) identificou que $87,1 \%$ dos pescadores artesanais de camarão, entrevistados no município de Porto Belo (SC), também migraram da pesca industrial.
Apesar da pesca industrial não constar como significativa na cidade, dados do Registro Geral da Pesca (MPA, 2015) mostram que há 113 inscritos na categoria de armador de pesca no município, o que evidencia que a atividade está presente entre os moradores locais. Uma parcela destes pescadores, ao se aposentarem ou após muitos anos na atividade, estão migrando para a pesca artesanal em busca de uma fonte complementar de renda (no caso dos aposentados) ou em busca de uma atividade que lhe ofereça um convívio maior com seus familiares (conforme relatos obtidos durante a pesquisa).

Os dados obtidos por Branco et al. (2006) mostraram que $78,0 \%$ dos pescadores informaram na época que já haviam atuado na atividade pesqueira em outros estados. De acordo com o perfil identificado nesta pesquisa, verifica-se que, prova- 
velmente, os autores citados estejam se referindo ao trabalho na pesca industrial, visto que a maioria $(94,4 \%)$ reside no município há mais de 30 anos, sendo pouco provável a atuação em outro estado por meio da pesca artesanal.

No caso do município de Penha, por meio dos dados disponíveis, observa-se que houve um aumento do número estimado de embarcações nos últimos 10 anos e um aumento do número de pescadores artesanais, bem como um incremento na biomassa de camarão capturada. Branco (2005) estimou em 68 barcos em atividade na Armação do Itapocoroy e uma produção anual de 170 toneladas de camarão; nesta pesquisa, foram contabilizadas 143 embarcações no município (sendo 81 na Armação). Estimativas mais recentes de produção apontam para 215 toneladas ao ano (Coelho et al., 2016) e para 165 embarcações em todo o município (UNIVALI, 2015). Percebe-se que não há evidências da diminuição da atividade pesqueira no município, e que a atividade mostra-se rentável, pois $95,0 \%$ dos pescadores entrevistados desejam continuar atuando.

A maioria dos pescadores moram há pelo menos 30 anos no município (94,4\%), e afirmou conseguir sustentar a família com a pesca $(72,7 \%)$, sugerindo um possível aumento da renda dos pescadores nesta comunidade. Quando os dados da pesquisa atual são comparados à pesquisa realizada em 2006, observa-se que $48,3 \%$ alegavam que conseguiam sustentar a família com essa atividade, sendo que apenas $23,7 \%$ possuía renda acima de dois salários mínimos (Branco et al., 2006). Na pesquisa atual, $72,2 \%$ informaram receber mais do que dois salários mínimos, e a renda mensal média oriunda da pesca variou entre um e sete salários. Para UNIVALI (2015), a renda mensal média da atividade foi de 2,29 salários mínimos.
O rendimento mensal dos pescadores está próximo ao salário médio mensal dos trabalhadores formais para este município, que é de 2,3 salários mínimos (IBGE, 2015). Quando são analisados os dados do ano de 2006, verifica-se que a renda dos pescadores estava abaixo do salário médio no município, que era de 2 salários mínimos (SEBRAE, 2013). Verificou-se que, apesar dos problemas relatados durante as entrevistas, $95,0 \%$ dos pescadores pretendem continuar na profissão, percentual superior ao encontrado por Branco et al. (2006) de $76.4 \%$, para a mesma cidade. Uma das possíveis razões para o aumento da renda do pescador está na agregação de valor ao pescado antes da comercialização, uma vez que $79,2 \%$ dos entrevistados afirmam que fazem algum tipo de beneficiamento no camarão antes da venda (a maioria descasca).

Verificou-se um número menor de pescadores filiados atualmente à colônia de pesca local (61,1\%); para Branco et al. (2006) esse percentual era de 97,7\%. Uma possível explicação para essa redução seria a pouca atuação da colônia de pesca local (como representação do pescador), e ainda a existência de uma associação local de pescadores, fundada em 2014, a qual também atua como entidade representante do setor no município. Dados de UNIVALI (2015) mostram que em torno de $76 \%$ dos pescadores informaram ser filiados a alguma entidade de apoio à pesca no município, o que permite afirmar que há um percentual menor de pescadores filiados a alguma entidade quando comparados ao ano de 2006.

Pode-se observar ainda que os motivos que levam os pescadores a filiarem-se a estas entidades estão relacionados à comprovação de sua atuação como pescador artesanal, para fins de recebimento 
do seguro defeso e não por terem nestas entidades um órgão que os representem (Acauan et al., 2018). A baixa representatividade destas entidades de classe é fator comum em muitas comunidades pesqueiras artesanais dos países em desenvolvimento (Jacinto \& Pomeroy, 2011).

Destaca-se em vários relatos que os pescadores afirmam não participar das reuniões da colônia e não procuram a entidade, por acreditar que a mesma não os representa, fato também relatado por Serafini et al. (2014). Registra-se que não foi possível entrevistar um representante da colônia: apesar do contato informal com o mesmo, foi o único pescador local que optou por não participar da pesquisa. Dentre as sugestões apontadas para melhoria da atividade, surgiu a criação de associação ou cooperativa, demonstrando a necessidade de uma maior organização deste público no município.

Contatou-se que, mesmo com a existência de duas entidades de classe no município, os pescadores atuam de forma individual, o que dificulta sua capacidade de negociação (Wamukota et al., 2014; Purcell et al., 2017), não existindo estrutura cooperativa. Cenário similar foi constatado em comunidades pesqueiras na Baia da Babitonga por Serafini et al. (2014), onde há 6 colônias e 7 associações, e mesmo assim a maioria dos pescadores atua de forma isolada. Jacinto \& Pomeroy (2011) alertam que uma das restrições vinculativas para o engajamento dos pescadores em pequena escala nos mercados é a fragmentação do setor, os pescadores operam em grande parte individualmente, tanto na produção quanto na comercialização de produtos da pesca.

\subsection{De volta à escola: uma nova perspectiva à atividade pesqueira artesanal?}

Dados relacionados à escolaridade dos pescadores artesanais em Penha mostram que 45,2\% dos entrevistados declararam possuir o ensino fundamental incompleto, e $22,6 \%$ o ensino médio completo. Quando comparados aos dados de Branco et al. (2006), para o mesmo público, quando apenas $1,8 \%$ dos pescadores possuíam ensino médio completo, observa-se uma mudança em relação ao nível de escolaridade na última década nesta comunidade, embora ainda predomine a escolaridade de nível fundamental entre os pescadores.

A baixa escolaridade é uma tendência observada na maioria das comunidades pesqueiras no Brasil (Garcez \& Botero, 2005; Souza et al., 2009; De Alencar \& Maia, 2011; Sedrez et al., 2013; Silva-Gonçalves \& D'Incao, 2016). Resultados semelhantes foram encontrados por Mendonça et al. (2017) em estudo sobre os pescadores no estado do Paraná, verificando um nível de escolaridade maior dos pescadores nos últimos 11 anos; de acordo com os autores, este fato pode ser um reflexo do aumento da escolaridade no país de forma geral na última década.

Verificou-se que a média de idade dos pescadores com ensino médio completo é de 32,8 anos, enquanto que a média daqueles com ensino fundamental incompleto é de 52,9 anos. Pode-se afirmar que os mais jovens estão entrando na atividade com um nível maior de escolaridade, um possível reflexo da maior acessibilidade à educação e da maior valorização dos estudos perante a sociedade, permitindo, neste caso, que o pescador entre na atividade por escolha e não por falta de opção. De 
acordo com Sedrez et al. (2013), os jovens filhos de pescadores artesanais estão buscando uma nova capacitação que no futuro poderá auxiliar seus pais na melhoria dos resultados financeiros obtidos com as pescarias, principalmente com a adoção de novas tecnologias.

Quando questionados em relação à possibilidade de voltar a estudar, 50,0\% dos pescadores declararam que retomariam os estudos, especialmente se os cursos fossem relacionados à sua atividade. Nesse sentido, alguns relatos de pescadores com idade mais elevada refletem a lógica do ensino básico no Brasil. Eles afirmaram durante as entrevistas que deixaram os estudos por não sentirem-se capazes de obter sucesso na escola; também relatam que a pesca tenha sido uma alternativa imposta pela então falta de escolaridade à época em que eram jovens, ou seja, desde então se sentem excluídos da sociedade.

Há muito, constata-se que a educação básica tenta vencer a lógica da exclusão; Arroyo (1992) já alertava para um sistema escolar que ia ao encontro das instituições sociais brasileiras geradas e mantidas para reforçar uma sociedade desigual e excludente, como parte da lógica e da política da exclusão que permeava as instituições sociais e políticas. A pesca surge neste cenário como um reflexo desta sociedade, ou seja, uma atividade que por muito tempo (e ainda nos dias atuais, preponderantemente) é uma (e muitas vezes considerada a única) alternativa para a parcela que pouco acesso teve à educação. De acordo com Garcez \& Botero (2005), a entrada de jovens na atividade pesqueira em estudo realizado no Rio Grande do Sul, deve-se às poucas oportunidades de ingresso destes em outras profissões, assim como à limitação para continuidade dos estudos.
Talvez estas estejam entre as principais razões pelas quais a atividade se apresenta no atual cenário na maioria das comunidades pesqueiras, e precisa de medidas que vão além das estratégias comuns à gestão pesqueira no Brasil. A atividade se desenvolveu tendo como base a baixa escolaridade da grande parcela de seus trabalhadores, situação que foi sendo mantida ao longo do tempo, com a ausência quase total de políticas públicas destinadas a modificar este quadro. Somente na última década verificam-se alguns sinais de que a situação possa mudar. Callou (2010), ao refazer o caminho histórico dos povos do mar no Brasil, conclui que as políticas públicas, passadas e contemporâneas são indiferentes às reivindicações dos pescadores, pautando-se na lógica capitalista do privilégio ao setor empresarial, bem como não incorporam a produção científica das universidades sobre as culturas tradicionais da pesca.

Nesta perspectiva, o incentivo à melhoria na formação dos trabalhadores da pesca artesanal está longe de ser uma prioridade, pois poderia reconstruir o cenário da pesca, com base numa estrutura de trabalho colaborativa e menos excludente. Sob a ótica de profissionalizar a atividade, o trabalhador tem a opção de escolher, e não de ser escolhido para atuar na pesca.

O que se observa atualmente é uma lenta, mas significativa mudança neste aspecto na comunidade pesquisada. Por meio de algumas ações observadas na região de estudo, o perfil do pescador começa a mudar. A presença de instituições de ensino, pesquisa e extensão, bem como órgãos de fiscalização e algumas mudanças na legislação, fazem com que o pescador precise voltar à escola, para cursos de qualificação profissional. Um exemplo é a recente alteração na legislação que trata do seguro-defeso 
para o pescador artesanal (especialmente a Instrução Normativa No 83/2015 PRES/INSS), a qual passa a exigir do pescador que trabalha embarcado a Caderneta de Inscrição e Registro, CIR, na categoria "Pescador Profissional" para o recebimento do seguro. Para registrar-se nesta categoria junto à Marinha do Brasil, o pescador precisa realizar um curso de qualificação de 84 ou 160 horas de duração (Brasil, 2017).

Voltar à escola parece ter um significado importante neste contexto; embora os cursos sejam de curta duração, atualmente a maioria das vagas destes cursos no Estado são ofertadas por um Instituto Federal de Educação, Ciência e Tecnologia, papel este anteriormente exclusivo da Marinha. Conforme relatos obtidos durante as entrevistas, o pescador, ao conviver novamente num ambiente escolar, agora num curso voltado à sua profissão, consegue trazer um novo significado para o aprender. Mesmo em pouco tempo, os resultados obtidos pela referida instituição mostram um caminho promissor na busca por um maior profissionalismo deste setor (Hickenbick et al., 2016).

\subsection{A atividade de pesca: um pouco sobre o dia a dia do pescador}

A modalidade de pesca mais praticada no local de estudo é de arrasto duplo, realizada por uma frota de embarcações artesanais com foco na captura de camarões, principalmente da espécie sete-barbas (Xiphopenaeus kroyeri). As embarcações desta modalidade pesquisadas possuem entre 6,5 e 10,2 metros de comprimento e são do tipo 'bote' ou 'baleeira', as baleeiras, diferentemente dos botes, tem como característica principal similaridade entre popa e proa. Estas embarcações são construídas, na sua totalidade, em madeira, sendo que $54,8 \%$ possuem casaria. Todas são motorizadas, com potências do motor variando entre 10 e $33 \mathrm{HP}$ (potência média de 22,21 $\pm 5,55$ ).

Os petrechos utilizados pelas embarcações são redes de arrasto de fundo, duas por embarcação, as quais se mantêm abertas graças ao auxílio de portas de madeira. Estas redes possuem comprimento médio de $11,09 \mathrm{~m} \pm 1,98$, fabricadas em poliamida multifilamento e polietileno, com malhas de tamanho que variam entre 18 e $40 \mathrm{~mm}$ na panagem.

Segundo os entrevistados, a atividade de pesca normalmente inicia entre as 4 e 5 h da manhã, com as embarcações navegando de 30 a 90 minutos até o local de pesca, e retornando no mesmo dia. A tripulação é composta em sua maioria por uma pessoa, como observado por Bail \& Branco (2007) e Sedrez et al. (2013), que desempenha todas as funções, desde a preparação dos materiais, a navegação, a pesca, a conservação e o desembarque do pescado. No entanto, $16,7 \%$ dos entrevistados informaram contar com auxílio de um ajudante de pesca.

A execução destas tarefas de forma solitária, especialmente a bordo, maximiza alguns dos riscos inerentes à atividade da pesca. Relatos de pescadores que sofrem desmaios, quedas e outros acidentes durante os arrastos não são incomuns no município. Cabe ressaltar que a pesca é reconhecidamente uma das profissões mais perigosas existentes, expondo seus trabalhadores a uma série de situações de risco todos os dias (Garrone Neto et al., 2005).

A situação descrita é ainda mais preocupante quando se observa que os pescadores não têm nas entidades locais um órgão de referência para sua classe. Nem mesmo conhecem muitos direitos que teriam. Também a maioria $(60,7 \%)$ não sabe quem 
procurar em caso de algum problema ou proposição de sugestão para a pesca, mesmo que mais de $90 \%$ estejam há mais de 10 anos atuando na atividade e morando no município há mais de 30 anos.

Esta informalidade da pesca artesanal (que resulta ainda em falta de licenças de pesca, documentos do pescador, emissão de nota fiscal) contribui para a ausência ou inadequação de políticas públicas para o setor, dificulta as tentativas de melhoria das condições de trabalho, e muitas vezes acaba mascarando os problemas da atividade. $\mathrm{O}$ fato dos pescadores não possuírem registros de trabalho formal, pouco acesso à qualificação, assim como dificuldades para acesso ao crédito formal, contribuem para a prevalência do comércio informal e do envolvimento limitado dos pescadores no processo de gestão em diversas comunidades no Brasil e no mundo (Peña-Torres, 2005; Salas et al., 2007; De Carvalho, 2012; Capelesso \& Cazella, 2013;).

\subsection{A pesca de arrasto e os desafios para a sustentabilidade na comunidade de penha}

Em relação à execução da captura do camarão, os entrevistados informaram que realizam os arrastos em profundidades que variam entre $8 \mathrm{e}$ 40 metros, sendo que a maioria atua entre os $10 \mathrm{e}$ 20 metros de profundidade, e o tempo médio dos arrastos está entre 60 e 90 minutos. O pescado é selecionado e armazenado a bordo, sendo devolvidos ao mar os organismos que apresentam baixo valor comercial. Dos pescadores analisados, 70,6\% afirmam que não utilizam nenhum produto para conservar o pescado, acondicionando a captura em cestos ou caixas até a chegada em terra. Essa prática parece ser comum na pesca artesanal de camarão sete barbas no litoral catarinense (Bail \& Branco, 2007; Sedrez et al., 2013)

A falta de padronização na conservação e manejo do pescado é um fator que pode ocasionar a desvalorização do produto; por ser uma pescaria de curta duração, os pescadores locais têm como prática utilizar gelo somente nos meses mais quentes do ano. O pescado integra o grupo dos alimentos altamente perecíveis e exige cuidados especiais, como a conservação pelo frio, já que também está sujeito à contaminação pelos mais variados microrganismos, adquiridos já no ambiente aquático ou durante as diferentes etapas de captura e transporte.

Porém, observa-se que o camarão mantido fora do gelo não é aceito em alguns estabelecimentos da cidade, que inclusive dispõe-se a pagar um preço melhor por um produto de qualidade superior. Por constituir-se um alimento com elevada perecibilidade, o pescado necessita de rigorosos cuidados de conservação a frio, para retardar as reações microbiológicas de contaminação e deterioração do produto, adquiridas da própria fauna do habitat do animal ou durante a sua cadeia produtiva de captura e transporte (Germano \& Germano, 2001). Como a maioria do pescado é comercializada por intermediários, os quais destinam a produção para terceiros realizarem o beneficiamento, estudos futuros que visem analisar a qualidade higiênico-sanitárias destes produtos são necessários.

De acordo com a pesquisa, todos os pescadores descartam total ou parcialmente a fauna acompanhante, a qual pode variar de 2 a $12 \mathrm{Kg}$ para cada $\mathrm{Kg}$ de camarão capturado (Branco \& Verani, 2006); 41,2\% utilizam parte para consumo próprio ou de familiares e $26,5 \%$ comercializam os peixes de maior tamanho. Pode-se considerar este como um dos fatores prioritários para análises 
relacionadas aos impactos ambientais da pesca no município, visto o aparente aumento do esforço de pesca e consequentemente dos descartes, pois não há registros da diminuição da captura de espécies não aproveitadas, ou do aumento da sua utilização ao longo dos anos.

Diversos estudos apontam que a pesca de arrasto, por ser pouco seletiva, tem índices elevados de descartes (Branco, 1999; Vianna \& Almeida, 2005; Rodrigues-Filho et al., 2016). De acordo com estudo realizado por Branco \& Verani (2006), no município de Penha, o impacto da pesca do camarão sete-barbas sobre a fauna acompanhante assume dimensões preocupantes, especialmente devido ao número elevado de juvenis que são devolvidos mortos ao mar; de acordo com os autores, na maioria dos estudos não existem dados suficientes para determinar os reais impactos biológicos, ecológicos, econômicos ou socioculturais da prática do descarte.

Davies et al. (2009) estimaram que o montante das capturadas de espécies não utilizadas na pesca marinha mundial (bycath) representa $40,4 \%$ das capturas marinhas globais, expondo importantes lacunas na política e gestão da pesca em todo o mundo. A falta de um monitoramento constante, especialmente na pesca artesanal, agrava ainda mais esta situação pois, na maioria das vezes, trata-se de comunidades tradicionais, com baixa escolaridade, em que a capacidade de encontrar alternativas para as práticas existentes ficam limitadas.

A utilização da fauna acompanhante (especialmente os peixes, que ocorrem em maior abundância) poderia incrementar a renda do pescador artesanal e diminuir consideravelmente o desperdício, assim como ocorre com a agregação de valor ao camarão já comercializado, cuja prática vem sendo realizada por algumas famílias. Diminuir o desperdício e incremen- tar o valor agregado ao pescado comercializado pelo pescador pode resultar numa diminuição do esforço de pesca para manter uma mesma renda média na comunidade. Seriam necessários, para isso, investimentos em capacitação e infraestrutura para o beneficiamento do pescado.

Indo ao encontro da diminuição dos impactos da pesca de arrasto, pesquisas têm testado a eficiência de equipamentos que minimizam a captura incidental, como os dispositivos para a redução da captura da fauna acompanhante (Broadhurst, 2000; Hannah \& Jones, 2007; Medeiros et al., 2013; Guanais et al., 2014). No Brasil os experimentos ainda necessitam ampliar as abordagens de forma multidisciplinar, envolvendo a avaliação também por parte dos pescadores (Guanais et al., 2014), mas mostram-se como uma alternativa viável para a redução dos descartes na pesca de arrasto. Mais uma vez verifica-se ser de fundamental importância a participação dos pescadores nestas ações, pois o sucesso destas estratégias dependerá, em última instância, de sua utilização por este público.

Diretrizes da FAO, para garantir a sustentabilidade da pesca em pequena escala, orientam para que as perdas e os resíduos sejam evitados, procurando maneiras de agregar valor, investindo em tecnologias tradicionais de custo eficiente, inovações locais e transferências de tecnologia culturalmente apropriadas (FAO, 2015). No município em estudo foram identificadas algumas práticas já comuns entre os familiares de pescadores, as quais proporcionam um valor agregado não somente ao camarão, mas a outras espécies capturadas. As principais dificuldades relatadas para que esta prática se expanda referem-se às barreiras burocráticas e à falta de orientações em relação à legalização, por exemplo, de estabelecimentos para o beneficiamento e a comercialização do pescado em pequena escala. 
As informações mostram que estas práticas configuram-se em estratégias adotadas pela comunidade para adaptar-se as mudanças no cenário socioeconômico local. Nos últimos anos é notório o crescimento de atividades ligadas ao turismo na região; somente no município de Penha estão cadastrados 144 estabelecimentos que trabalham com serviço de alimentação e bebidas, muitos dos quais adquirem camarão e outros pescados durante o ano todo.

\section{Considerações finais}

Os dados da pesquisa mostram que a atividade de pesca artesanal apresenta-se inserida no cotidiano do município em estudo, embora mudanças significativas aconteçam nos processos produtivos ao longo dos anos. Observam-se indícios de que os pescadores adaptam-se as mudanças, e têm mantido a pesca como uma importante fonte de renda no município, inclusive com incremento em sua renda.

Diegues (2001) relata que, apesar do modo de produção capitalista se apropriar da produção artesanal na pesca, não necessariamente desorganiza esse modo de produção e reprodução social; de acordo com o autor, um exemplo são os muitos trabalhadores que saem de suas comunidades para atuar em empresas, ou num barco de pesca industrial, mas retornam posteriormente como produtores autônomos, comprando, por exemplo, seu próprio barco de pesca onde trabalham com suas famílias. De acordo com os relatos obtidos durante as entrevistas no município de Penha, este é o caso de muitos pescadores que optaram pela pesca artesanal.

A pesca, quando inserida num contexto social e familiar, vai além de uma atividade econômica; per- meia a cultura, os costumes, os gostos, desgostos, e até mesmo os sonhos daqueles que se reconhecem como homens e mulheres do mar. Faz parte do dia a dia, de quem pesca e de todos ao redor; por isso ao pensar em estratégias para uma pesca sustentável, não há como desconsiderar este contexto. O difícil é contemplá-lo, pois as informações (quando disponíveis) encontram-se isoladas, descontínuas e descontextualizadas, resultando em muitas conclusões equivocadas.

A análise que comparou dados socioeconômicos da pesca nos últimos 10 anos evidencia a necessidade urgente de um monitoramento constante e participativo da pesca artesanal, visto que para muitas das informações obtidas não foram encontraram parâmetros de comparação ao longo dos anos.

\section{Conclusões}

A atividade de pesca artesanal vem se mantendo nos últimos anos no município de Penha (SC), apresentando inclusive indícios de crescimento tanto em número de embarcações e pescadores, quanto em produção e renda, de acordo com os dados disponíveis. É necessário, porém, que se estabeleça um monitoramento (preferencialmente de forma participativa) da pesca artesanal permitindo uma análise mais ampla do contexto socioeconômico e ambiental.

Há uma renovação da pesca artesanal nesta comunidade, por meio de pescadores com faixa etária mais elevada, que migram da pesca industrial, em busca de uma complementação na renda (quando aposentados) ou de melhores condições de trabalho. Neste sentido, a faixa etária média mais elevada dos pescadores não significa necessariamente que não 
haja a entrada de novos pescadores na atividade. Por outro lado, os pescadores mais jovens que estão ingressando na atividade o fazem com um nível de escolaridade maior, o que refletiu num aumento da escolaridade média do pescador artesanal nos últimos anos no município em estudo.

Estes fatos evidenciam que a atividade faz parte do cotidiano das pessoas envolvidas, e que, ao que tudo indica, a entrada na pesca artesanal tem sido uma opção, tanto dos mais jovens (que tem procurado uma melhor formação para o desempenho da atividade) quanto dos mais velhos (que, entre a pesca industrial e artesanal, optam pela última, nesta comunidade).

Os dados disponíveis para a pesca artesanal no local de estudo ao longo dos anos são insuficientes para uma análise dos impactos, bem como para a proposição de conclusões referentes à sustentabilidade desta atividade ao longo dos anos. No entanto, permitem identificar que a pesca atualmente é uma atividade economicamente rentável ao pescador artesanal, cujo papel sociocultural enquanto atividade laboral vem se mantendo ao longo dos anos.

\section{Referências}

Acauan, R. C.; Teixeira, B.; Polette, M.; Branco, J. O. Aspectos legais da pesca artesanal do Camarão sete-barbas no município de Penha, SC: o papel do defeso. Interações, 19(3), 543-556, 2018. Disponível em http://www.interacoes. ucdb.br/article/view/158.

Allison, E. H.; Ratner, B. D.; Asgard, B.; Willmann, R.; Pomeroy, R.; Kurien, J. Rights based fisheries governance: from fishing rights to human rights. Fish and Fisheries, 13(1), 14-29, 2012. doi: 10.1111/j.1467-2979.2011.00405.x

Almeida, L. R.; Branco, J. O. Aspectos biológicos de Stelliferstellifer na pesca artesanal do camarão sete-barbas, Ar- mação do Itapocoroy, Penha, Santa Catarina, Brasil. Revista brasileira de Zoologia, 19(2), 601-610, 2002.

Arroyo, M. Qualidade Totalfina educação-total mesmo. Belo Horizonte: Assembleia Legislativa, 1992.

Bail, G. C.; Branco, J. O. Pesca artesanal do camarão sete-barbas: uma caracterização sócio-econômica na Penha, SC. Brazilian Journal of Aquatic Science and Technology, 11(2), 25-32, 2007.

Bail, G. C.; Branco, J. O. Branco. Ocorrência, abundância e diversidade da ictiofauna na pesca do camarão sete-barbas, na Região de Penha, SC. Notas Téc. FACIMAR, 7, 73-82, 2003.

Béné, C. Small-scale fisheries: assessing their contribution to rural livelihoods in developing countries. FAO Fisheries Circular. No. 1008. Rome, FAO. 2006. 46p.

Berkes, F. Managing small-scale fisheries: alternative directions and methods. IDRC, 2001.

Branco, J. O. Avifauna aquática do Saco da Fazenda (Itajaí, Santa Catarina, Brasil): uma década de monitoramento. Revista Brasileira de Zoologia, 24(4), 873-882, 2007.

Branco, J. O. Biologia e pesca do camarão sete-barbas Xiphopenaeuskroyeri (Heller) (Crustacea, Penaeidae), Penaeidae), Penaeidae), na Armação do Ita mação do Ita mação do Itapocoroy, Penha, Santa Catar Santa Catar Santa Catarina, Brasil. Revista Brasileira de Zoologia, 22(4), 1050-1062, 2005.

Branco, J. O. Biologia do Xiphopenaeus kroyeri (Heller, 1862) (Decapoda: Penaeidae), análise da fauna acompanhante e das aves marinhas relacionadas a sua pesca, na região de Penha, SC, Brasil. Tese (Doutorado). Universidade de São Carlos, SP, 1999.

Branco, J. O.; Bail, G. C.; Verani, J. R.; Marenzi, A. W. C. Aspectos sócio-econômicos da pesca artesanal do camarão sete-barbas (Xiphopenaeuskroyeri), na região de Penha, SC. In: Branco, J. O.; Marenzi, A. W. C. (org.). Bases ecológicas para um Odesenvolvimento sustentável: estudos de caso em Penha, SC. Editora da UNIVALI, Itajaí. 292p. 2006.

Branco, J. O.; Fracasso, H. A. A. Ocorrência e abundância da carcinofauna acompanhante na pesca do camarão sete-barbas, Xiphopenaeuskroyeri Heller (Crustacea, Decapoda), 
na Armação do Itapocoroy, Penha, Santa Catarina, Brasil Revista brasileira de Zoologia, 21(2), 295-301, 2004.

Branco, J. O.; Santos, L. R.; Barbieri, E.; Santos, M. C. F.; Rodrigues Filho, J. L. Distribuição espaço-temporal das capturas do camarão sete-barbas na Armação do Itapocoroy, Penha, SC. Boletim do Instituto de Pesca, 39(3), 237-250, 2013.

Branco, J. O.; Verani, J. R. Pesca do camarão sete-barbas e sua fauna acompanhante, na Armação do Itapocoroy, Penha, SC. In: Branco, J. O.; Marenzi, A. W. C. (org.). Bases ecológicas para um Odesenvolvimento sustentável: estudos de caso em Penha, SC. Editora da UNIVALI, Itajaí. p. 153-170. 2006.

Brasil. Programa do Ensino Profissional Marítimo para Aquaviários- PREPOM. Diretoria de Portos e Costas. Marinha do Brasil. 2017.

Broadhurst, M. K. Modifications to reduce bycatch in prawn trawls: a review and framework for development. Reviews in Fish Biology and Fisheries, 10(1), 27-60, 2000.

Callou, A. B. F. Povos do mar: herança sociocultural e perspectivas no Brasil. Ciência e Cultura, 62(3), 45-48, 2010.

Capellesso, A. J.; Cazella, A. A. Os sistemas de financiamento na pesca artesanal: um estudo de caso no litoral centro-sul catarinense. Revista de Economia e Sociologia Rural, 51(2), 275-294, 2013.

Castello, L. Re-pensando o estudo eo manejo da pesca no Brasil. Pan-American Journal of Aquatic Sciences, 3, 17-22, 2008.

Coelho, V. F.; Branco, J.; Harms Dias, M. A. Indicadores de produtividade aplicados à pesca artesanal do camarão sete-barbas, Penha, SC, Brasil. Ambiente \& Água - An Interdisciplinary Journal of Applied Science, 11(1), 2016.

Davies, S. J.; Cripps, A. N.; Porter, G. Defining and estimating global marine fisheries bycatch. Marine Policy, 33(4), 661-672, 2009.

De Alencar, C. A. G.; Maia, L. P. Perfil socioeconômico dos pescadores brasileiros. Arquivos de Ciências do Mar, 44(3), 12-19, 2011.

De Carvalho, D. R. A importância da gestão compartilhada e das áreas marinhas protegidas para o sistema socioecológico da pesca artesanal: $\mathrm{O}$ caso das reservas extrativistas marinhas. GeoTextos, 8(2), 97-121, 2012.

Dias Neto, J. Instituto Brasileiro do Meio Ambiente e dos Recursos Naturais Renováveis. Análise do seguro-desemprego do pescador artesanal e de possiveis beneficios para a gestão pesqueira / José Dias Neto. Brasília: Ibama, 2017. 120 p. ; Il. Color. ISBN 978-85-7300-385-7

Diegues, A. C. S. O mito moderno da natureza intocada. 3.a ed. São Paulo: NUPAUB, 2001. 161 p.

Eler, M. N.; Millani, T. J. Métodos de estudos de sustentabilidade aplicados a aquicultura. Revista Brasileira de Zootecnia, 36, 33-44, 2007.

FAO. The State of World Fisheries and Aquaculture 2016. Contributing to food security and nutrition for all. Rome: FAO. 2016. 200p.

FAO. Voluntary guidelines for securing sustainable small-scale fisheries in the context of food security and poverty eradication. Rome, 2015. 34p

Garcez, D. S.; Botero, J. I. S. Comunidades de pescadores artesanais no estado do Rio Grande do Sul, Brasil. Atlântica, 27(1), 17-29, 2005

Garrone Neto, D.; Cordeiro, R. C.; Haddad Jr, V. Acidentes do trabalho em pescadores artesanais da região do Médio Rio Araguaia, Tocantins, Brasil. Cadernos de Saúde Pública, 2005.

Germano, P. M. L.; Germano, M. I. S. Agentes bacterianos de toxinfecções. Higiene e Vigilância Sanitária de Alimentos. São Paulo: Livraria Varela, 199-258, 2001.

Gillett, R. Marine fishery resources of the Pacific Islands. Food and Agriculture Organization of the United Nations (FAO), 2010.

Guanais, J. H. D. G., Medeiros, R. P., Spach, H. L., Cattani, A. P.; de Oliveira Santos, L. Uso de dispositivos tecnológicos para a redução da captura de braquiúros pela pesca artesanal de arrasto. Arquivos de Ciências do Mar, 47(1), 54-63. 2014.

Hannah, R. W.; Jones, S. A. Effectiveness of bycatch reduction devices (BRDs) in the ocean shrimp (Pandalusjordani) 
trawl fishery. Fisheries Research, 85(1), 217-225, 2007.

Hickenbick, C.; Ramos, E. E. L.; Acauan, R. Certificação de Saberes Profissionais de Trabalhadores... In: III Encontro Internanional de Alfabetização e Educação de Jovens e Adultos, 2016, Florianópolis., 2016, Florianópolis Santa Catarina. In: III Encontro Intercanional de Alfabetização e Educação de Jovens e Adultos, 2016, Florianópolis. Anais do III AlfaeEja, 2017. v. 1., 2016.

IBGE. Instituto Brasileiro de Geografia e Estatística. Cadastro Central de Empresas. Salário médio mensal dos trabalhadores formais. Disponível em: https://cidades.ibge.gov. br/brasil/sc/penha/panorama. Acesso em 20/11/2017. 2015.

IBGE. Instituto Brasileiro de Geografia e Estatística. Diretoria de Pesquisas, Coordenação de População e Indicadores Sociais, Estimativas da população residente com data de referência $1^{\circ}$ de julho de 2017. Disponível em: https:// http:// cod.ibge.gov.br/2VVPS. Acesso em 18/09/2017. 2017.

Iles, A. Making the seafood industry more sustainable: creating production chain transparency and accountability. Journal of Cleaner Production, 15(6), 577-589, 2007.

Jacinto, E. R.; Pomeroy, R. S. Developin markets for small-scale fisheries: utilizing the value chain approach, In: Small-Scale Fish. Manag. Fram. Approaches Dev. World, CABI. 160-177. 2011.

Koerich, M. S.; Backes, D. S.; de Sousa, F. G. M.; Erdmann, A. L.; Alburquerque, G. L. Pesquisa-ação: ferramenta metodológica para a pesquisa qualitativa. Revista Eletrônica de Enfermagem, 11(3). 2009.

Kurien, J. Voluntary guidelines for securing sustainable small-scale fisheries in the context of food security and poverty eradication: Summary. 2015.

Marconi, M. D. A.; Lakatos, E. M. Técnicas de pesquisa. São Paulo: Atlas, 2002.

Medeiros, R. P. Estratégias de pesca e uso dos recursos em uma comunidade de pescadores artesanais da praia do Pântano do Sul (Florianópolis, Santa Catarina). Campinas. 113p. (Dissertação de Mestrado em Ecologia, Unicamp). 2002.

Medeiros, R. P.; Guanais, J. H. D. G.; Santos, L. D. O.; Spach, H. L.; Silva, C. N. S.; Foppa, C. C.; Rainho, A. P.
Estratégias para a redução da fauna acompanhante na frota artesanal de arrasto do camarão sete-barbas: perspectivas para a gestão pesqueira. Boletim do Instituto de Pesca, 39(3), 339-358, 2013.

Mendonça, J. T.; Lucena, A. C. M.; Muehlmann, L. D.; Medeiros, R. P.Socioeconomia da pesca no litoral do estado do Paraná (Brasil) no período de 2005 a 2015. Desenvolvimento e Meio Ambiente, 41, 2017.

MPA. Ministério da Pesca e Aquicultura. Boletim Estatístico da Pesca e Aquicultura. Disponível em: http:// bibspi.planejamento.gov.br/handle/iditem/191. Acesso em 20/04/2017. 2011

MPA. Mapa da Pesca e da Aquicultura no Brasil. Disponível em: http://www.brasil.gov.br/economia-e-emprego/2015/03/ ministerio-da-pesca-querquadruplicar-producao-aquicola-no-brasil. Acessoem 20/02/2017. 2015

Peña-Torres, J. Informal Markets, Perishability and Vertical Control: Brokerage of Artisanal Landings. Univ., Departamento de Economia y Administracion, 2005.

Purcell, S. W.; Crona, B. I.; Lalavanua, W.; Eriksson, H. Distribution of economic returns in small-scale fisheries for international markets: A value-chain analysis. Marine Policy, 86, 9-16, 2017.

Rodrigues-Filho, J. L.; Couto, E. D. C. G.; Barbieri, E.; Branco, J. O. Ciclos sazonais da carcinofauna capturada na pesca do camarão-sete-barbas, Xiphopenaeus kroyeri no litoral de Santa Catarina. Boletim do Instituto de Pesca, 42(3), 648-661. 2016.

Rosales, R. M.; Pomeroy, R.; Calabio, I. J.; Batong, M.; Cedo, K.; Escara, N.; Facunla, V.; Gulayan, A.; Narvadez, M.; Sarahadil, M.; Sobrevega, M. A. Value chain analysis and small-scale fisheries management. Marine Policy, 83, 11-21, 2017.

Salas, S.; Chuenpagdee, R.; Seijo, J. C.; Charles, A. Challenges in the assessment and management of small-scale fisheries in Latin America and the Caribbean. Fisheries Research, 87(1), 5-16, 2007.

Santos, R. A.; Camara, J. J. C.; Campos, E. C.; Vermulm-Junior, H.; Giamas, M. T. D. Considerações sobre a pesca profissional e a produção pesqueira em águas continentais 
do Estado de São Paulo. Boletim Técnico do Instituto de Pesca, São Paulo, 19, 32p. 1995.

SEBRAE/SC. Santa Catarina em Números: Penha/Sebrae/ SC._Florianópolis: Sebrae/SC. 132p. 2013.

Sedrez, M. C.; Santos, C. F.; Marenzi, R. C.; Sedrez, S. T.; Barbieri, E.; Branco, J.O. Caracterização socioeconômica da pesca artesanal do camarão setebarbas em Porto Belo, SC. Boletim do Instituto de Pesca, 39(3), 311-322, 2013.

Serafini, T. Z.; Andriguetto-Filho, J. M.; Pierri, N. Subsídios para a gestão compartilhada da pesca na Baía da Babitonga (SC, Brasil). Brazilian Journal of Aquatic Science and Technology, 18(1), 99-111, 2014.

Silva-Gonçalves, R.; D'Incao, F. Perfil socioeconômico e laboral dos pescadores artesanais de camarão-rosa no complexo estuarino de Tramandaí (RS), Brasil. Boletim do Instituto de Pesca, 42(2), 387-401, 2016.

Souza, K. M.; Casarini, L. M.; Henriques, M. B.; Arfelli, C. A.; Graça-Lopes, R. D. Viabilidade econômica da pesca de camarãosete-barbas com embarcação de pequeno porte na Praia do Perequê, Guarujá, Estado de São Paulo. Informações Econômicas, 39(4), 30-37. 2009.
Thiollent, M. Metodologia da pesquisa-ação. 11 ed. São Paulo: Vozes. 2002.

UNIVALI. Universidade do Vale do Itajaí. Projeto $\mathrm{Ca}$ racterização Socioeconômica das Atividades de Pesca e Aquicultura em Santa Catarina (PCSPA-SC). Vol. 1. 2015.

Wamukota, A.; Brewer, T. D.; Crona, B. Market integration and its relation to income distribution and inequality among fishers and traders: The case of two small-scale Kenyan reef fisheries. Marine Policy, 48, 93-101, 2014.

Vianna, M.; Almeida, T. Bony fish bycatch in the Southern Brazil pink shrimp (Farfantepenaeusbrasiliensis and F. paulensis) fishery. Brazilian Archives of Biology and Technology, 48(4), 611-623, 2005.

Viegas, M. C. M. Comunidades piscatórias e bio-recursos marinhos: estratégias para políticas de desenvolvimento e de gestão sustentáveis. 2012. 239f. Tese (Doutorado) Universidade Nova de Lisboa, Faculdade de Ciências e Tecnologia. Lisboa, 2012. 